IMECE2009-11244

\title{
TIME AVERAGED AND FLUCTUATING HEAT TRANSFER MEASUREMENTS IN AN ATOMISING MIST JET NOZZLE
}

\author{
Oisín F. P. Lyons \\ University of Dublin, Trinity College \\ Dublin, Ireland \\ Gerard Byrne \\ University of Dublin, Trinity College \\ Dublin, Ireland
}

\author{
Darina B. Murray \\ University of Dublin, Trinity College \\ Dublin, Ireland \\ Tim Persoons \\ University of Dublin, Trinity College \\ Dublin, Ireland
}

\begin{abstract}
Much is already known about the heat transfer characteristics of impinging air jets, and they are widely used in many engineering applications. There currently exist many correlations describing such characteristics. However, the complex internal structure of many nozzles can lead these to produce results which deviate from those predicted by correlations. One such nozzle is currently used in this research group to produce a water mist flow and this paper describes the experimental characteristics of its single phase behaviour.
\end{abstract}

\section{INTRODUCTION}

Impinging air jets have long been known to achieve superior heat transfer coefficients, with the variation in their local heat transfer coefficients also lending itself to application in areas of large temperature gradients. Their ability to achieve effective cooling rates has led to the implementation of jet cooling in many situations including the replacement of lubricants in some machining operations. Previous work in the research group investigated their effect on grinding temperatures [1].

It is believed that the implementation of a fine water mist into the air stream has the potential to further increase the heat transfer rates. Indeed, Lee et al. [2] state that at droplet diameters of $30-80 \mu \mathrm{m}$, a "superbly effective cooling scheme" is present. Convective heat transfer coefficients can increase by up to 10 times, through evaporation of an "ultra-thin" liquid film $(50-100 \mu \mathrm{m})$. The dispersal of water droplets into an air flow can be characterised as either spray cooling or mist jet cooling. A spray is obtained by pressurising the water in the nozzle in order to atomize it. Mist jets use the air pressure to atomize the water. Mist jets thus allow smaller droplet size [3]. The liquid flow can be controlled with less atomization constraints.

The nozzle geometry affects both the flow exit profile and the turbulence characteristics of the resulting far field flow. The flow structure will influence the local heat transfer distribution, through changes in entrainment and mixing of the thermal boundary layer. Thus, the effect of the nozzle exit shape on the velocity profile will also impact on heat transfer distributions [4]. The complex internal structure of the atomizing nozzle leads to increased free stream turbulence, which has been noted by Viskanta [5] to increase the surface heat transfer rate. Thus, the air jet itself is expected to give higher heat transfer coefficients than correlations predict $[6,7]$. 


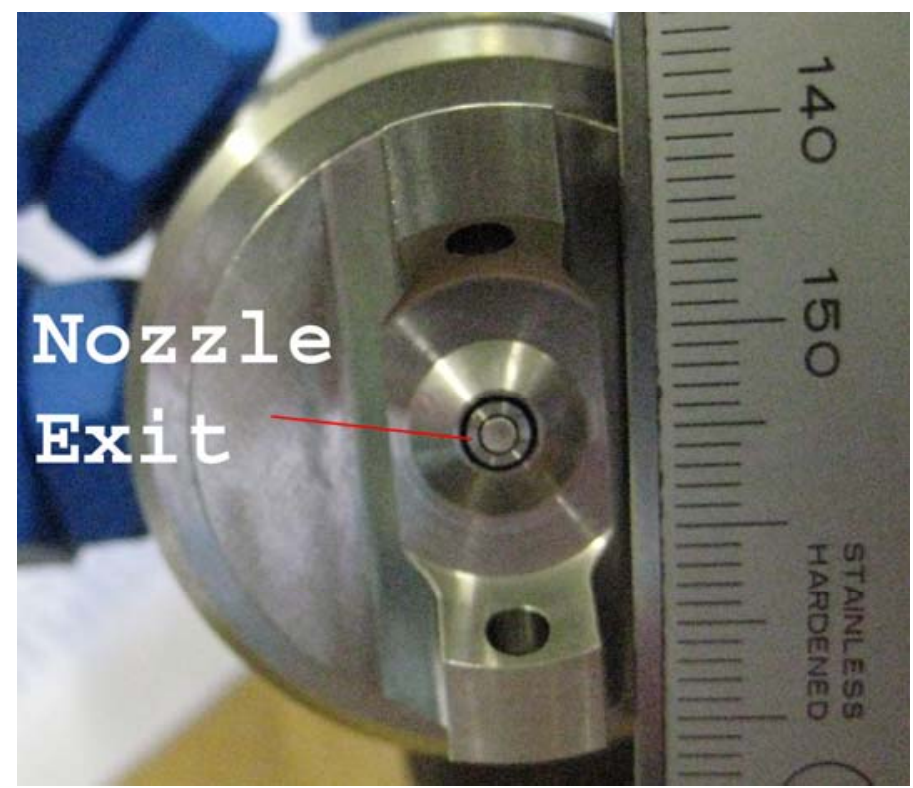

Figure 1: Nozzle profile

Chatterjee and Deviprasath [4] showed that the surface heat transfer coefficient can be influenced by the nozzle velocity distribution and thus by the nozzle exit conditions. Thus, nozzles of different geometries can have different heat transfer profiles, even for identical Reynolds numbers and nozzle-to-surface spacings. This effect becomes diminished at large $H / D$ values. Kito et al [8] also showed the effect of the contraction area ratio on surface heat transfer measurements.

The effect of angle of impingement is to relocate the maximum heat transfer coefficient. This occurs because the stagnation point is displaced in the direction of the angle, $\mathrm{O}^{\prime}$ Donovan and Murray [9], Goldstein and Franchett [10].

The stagnation Nusselt number for a single round impinging jet with short sharp-edged orifice increases with Reynolds number as indicated by the correlation of Lui and Sullivan (valid 10,000 $<R e<30,000$ ) [11].

$$
\begin{aligned}
& N u_{0}=0.585 \operatorname{Re}^{0.5} \operatorname{Pr}^{0.4} \\
& H / D<2
\end{aligned}
$$

It is expected that the more complex nozzles will achieve similar dependencies.

Garimella and Rice [12] noted that conventional Nusselt number correlations fail to capture the heat transfer effect at low jet diameters. Pence et al [13] show that the fluid flow is dynamically different at the micro scale.

The hydraulic diameter $D_{H}$, calculated in the next section, has been used in the calculation of Reynolds number, the normalized nozzle exit to impingement spacing, $H / D$ and the normalized radial location, $r / D$. Ichimiya [14] proposed that $D_{H}$ should be used in the calculation of Re, but that the outer diameter should be used for $H / D$ and $r / D$ in the case of an annular jet.

This paper seeks to compare time averaged heat transfer coefficients from several different nozzles. Two nozzles are simple round air jet nozzles, of diameter $13.4 \mathrm{~mm}$ and $0.912 \mathrm{~mm}$, made of brass piping and stainless steel. The other nozzle is an atomizing nozzle, Spraying Systems Co., involving a complex nozzle body, with air exiting through an annular hole, nominal diameter $0.68 \mathrm{~mm}$, figure 1 . This nozzle will ultimately be used to investigate an air flow with entrained mist particles, but in the current investigation is restricted to air flow only.

The objective is to characterize an atomizing nozzle, as interpretation of mist effects requires a comprehensive knowledge of air only characteristics. Due to the small size and complex geometry, there is a need to compare with more conventional geometry, hence the two baseline tests comparing two impinging jets with circular, unconfined pipe nozzles with different diameters.

\section{EXPERIMENTAL SET-UP}

In order to fully understand the heat transfer effects of the mist jet, a series of nozzles are used; (i) an atomizing nozzle, supplied by Spraying Systems, which can generate a water mist in air flow, but is used only with air, (ii) a circular nozzle of $13.4 \mathrm{~mm}$ diameter which acts as a standard reference to air only flow, and (iii) a circular nozzle of $0.912 \mathrm{~mm}$ diameter which has a similar cross sectional area to that of the atomizing nozzle. This nozzle is used to allow compressibility aspects to be differentiated from geometry effects.

A rig was built to investigate the effects of nozzle geometry on the heat transfer to an impinging jet. The test surface is an instrumented isothermally heated copper plate. In order to measure the local heat flux transferred from the surface to the jet flow, a hot film sensor and thermopile heat flux sensor are mounted flush with the copper plate. The thermopile sensor is used for obtaining time averaged data whereas the hot film sensor is used to obtain fluctuating heat transfer measurements. Ambient, test surface, and nozzle fluid temperatures are recorded by several thermocouples. A stepper motor is used to move the test surface with respect to the fixed nozzle, so as to achieve full field measurements.

Data acquisition is via a National Instruments chassis containing analogue and digital input and output modules and a thermocouple module. The thermopile sensors used are $\mathrm{RdF}$ MicroFoil 27036 sensors. The signal is amplified before being fed to the data acquisition system. Labview controls all the data 
handling. Figure 2 shows the schematic of the test apparatus, with $H$, the nozzle exit to plate distance.

The heat transfer measurement approach has been validated for an impinging air jet against known correlations described in the literature [11, 15, 16] and other experimental rigs. Extensive calibration was performed on the thermocouples with a factory calibrated RTD probe connected to an Omega thermometer. The microfoil sensor was calibrated using an air jet with circular nozzle of diameter $13.4 \mathrm{~mm}$. The nozzle was positioned at a jet-to-surface distance $H / D$ of 0.75 . The calibration was performed using the Liu and Sullivan correlation (see equation 1), relating the stagnation Nusselt number to the Reynolds number [11]. The Reynolds number was varied between 10,000 and 20,000.

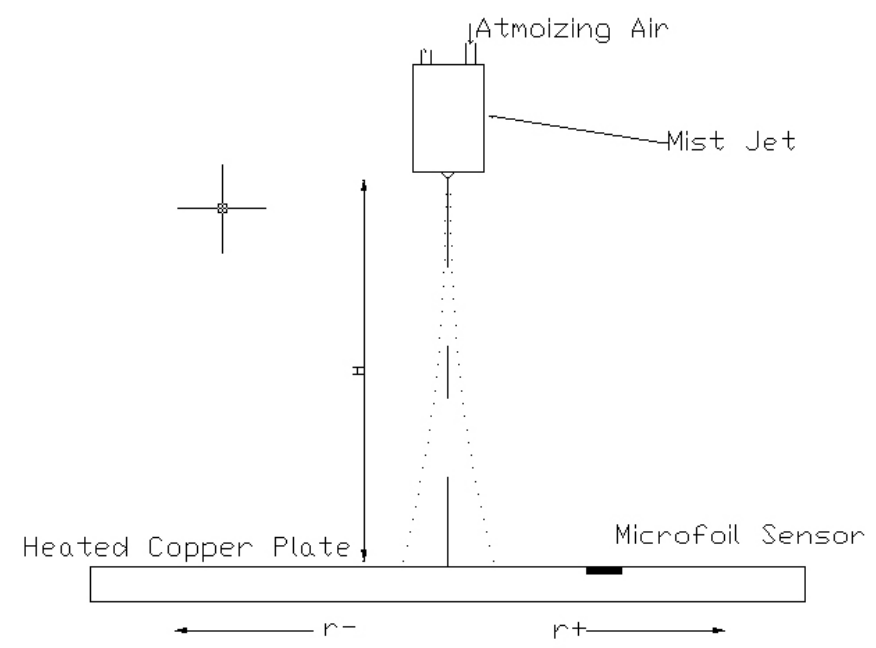

Figure 2: Schematic of the test apparatus

The hydraulic diameter, used for the atomizing nozzle has been defined as four times the cross sectional area $(A)$ divided by the wetted perimeter $(P)$.

$$
D_{H}=\frac{4 A}{P}
$$

There exist several ways in which the characteristic length is defined for an annular jet, [17, 14]. Chattopadhyay [15] uses the inner diameter and by choosing the outer diameter to be $\sqrt{2}$ times the inner allows a mass flux equivalent to that of a circular jet of radius equal to that of the inner radius. This approach allows the mass flows through the mass flows in both nozzles to be identical, which is clearly an interesting approach. The atomizing nozzle has preset inner and outer radii to optimise droplet formation. This meant the outer diameter could not be set to the $\sqrt{2}$ times the inner, so this approach was impractical. A similar approach involves matching the mass flux to that of a circular jet. Due to previous use in the department, the hydraulic diameter was chosen; this value is then used as the characteristic length (D) in all Reynolds number, Nusselt number, H/D and r/D spacing. The exit geometry of the atomizing nozzle can be seen in figure 1 and is of an annular profile. The nominal or hydraulic diameter has been calculated as $0.68 \mathrm{~mm}$. The smaller pipe nozzle has a diameter of $0.912 \mathrm{~mm}$. As can be seen from figure 2, the position of the nozzle relative to the test rig can be varied, so as to achieve full field measurements. There is a degree of confinement associated with both the atomizing and pipe nozzles. Thus, for the $0.921 \mathrm{~mm}$ nozzle, Mach numbers of 0.3 are reached at Reynolds numbers of 10,000. Likewise, Mach numbers of 0.4 at Reynolds numbers of 10,000 are seen in the atomizing nozzle. Due to these high exit velocities, the Reynolds number calculation must take into account static pressure and temperature values [12, 13].

$$
h=\frac{\ddot{q}_{c o n v}}{T_{s}-T_{j e t}}
$$

Heat transfer coefficients associated with the jets are based on the temperature of the air jet flow, as indicated in equation 3. This is measured by the air mass flow meter immediately upstream of the nozzle, and is typically $22^{\circ} \mathrm{C}$. The static temperature can drop below this jet temperature by several degrees. This can lead to the adiabatic temperature dropping to $20^{\circ} \mathrm{C}$ at high Reynolds numbers. It is the intention to investigate this effect fully in the future.

For future mist jet testing, additional elements of the rig include a water gear pump, pressure and flow meters. This enables water to be pumped to the atomising nozzle at high pressure. Water droplets are thus dispersed into an airstream, creating a mist flow.

\section{RESULTS AND DISCUSSION}

Nusselt number profiles for the $13.4 \mathrm{~mm}$ diameter nozzle have shown similar trends to that of previous literature, O' Donovan and Murray [9]. The traditional bell-shaped curve of decreasing Nusselt number with increasing r/D values can be seen from figures 3 and 4 . At low H/D values, typical secondary peaks are also evident at approximately two diameters out from the stagnation point. 


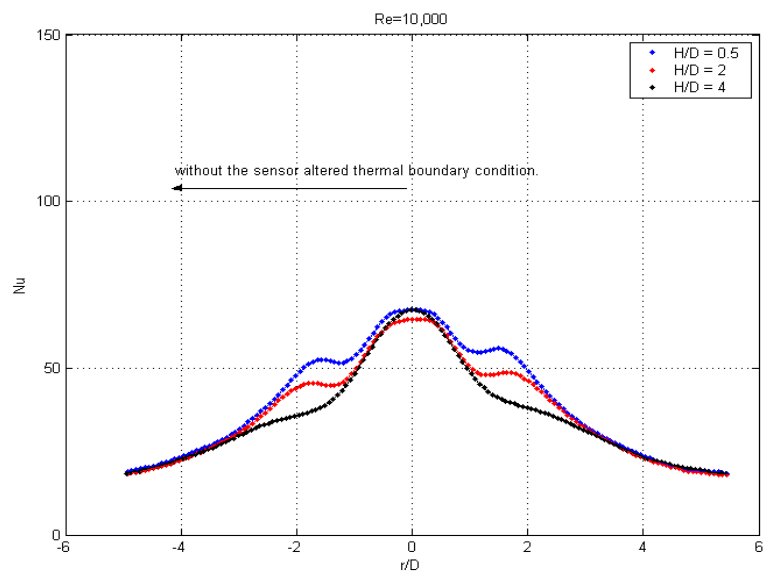

Figure 3: $D=13.4 \mathrm{~mm}$; Reynolds number of10,000; Varying H/D ratio

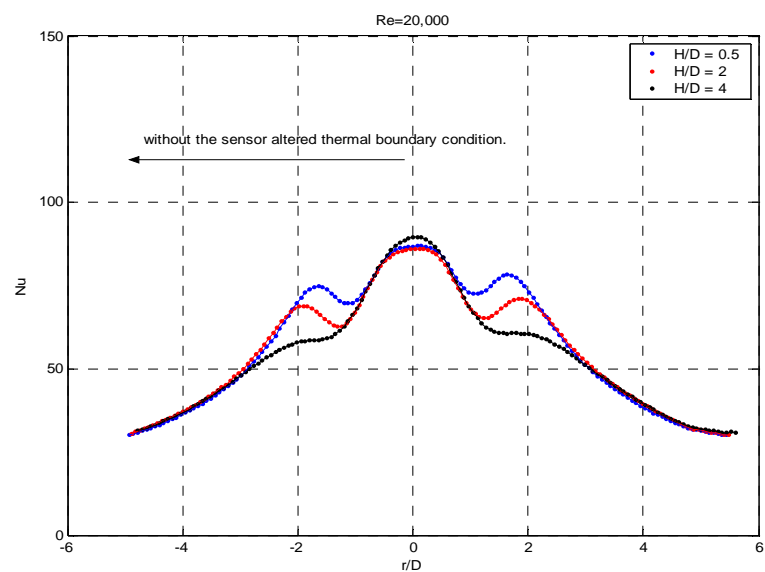

Figure 4: $D=13.4 \mathrm{~mm}$; Reynolds number of 20,000; Varying H/D ratio

In figures 3 and 4 a small degree of asymmetry is evident in the profiles. When the jet is positioned to the right of the sensor, the flow must pass over the body of the sensor before the heat transfer is recorded. This disturbance, both thermal and hydrodynamic, causes the sensor to read slightly elevated readings [9]. Thus the values given on the left hand side are deemed more accurate due to the position of the sensor.

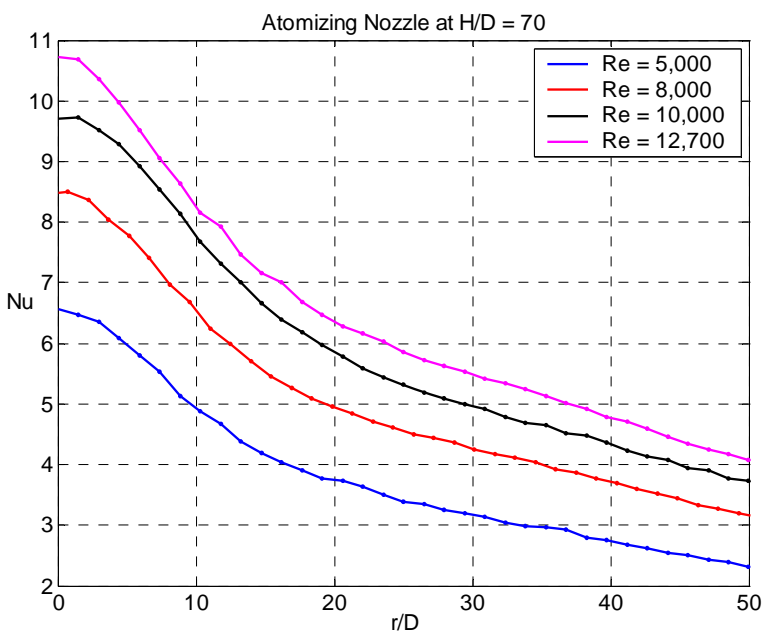

Figure 5: $D=0.68 \mathrm{~mm}$; Reynolds number varied; $H / D=70$

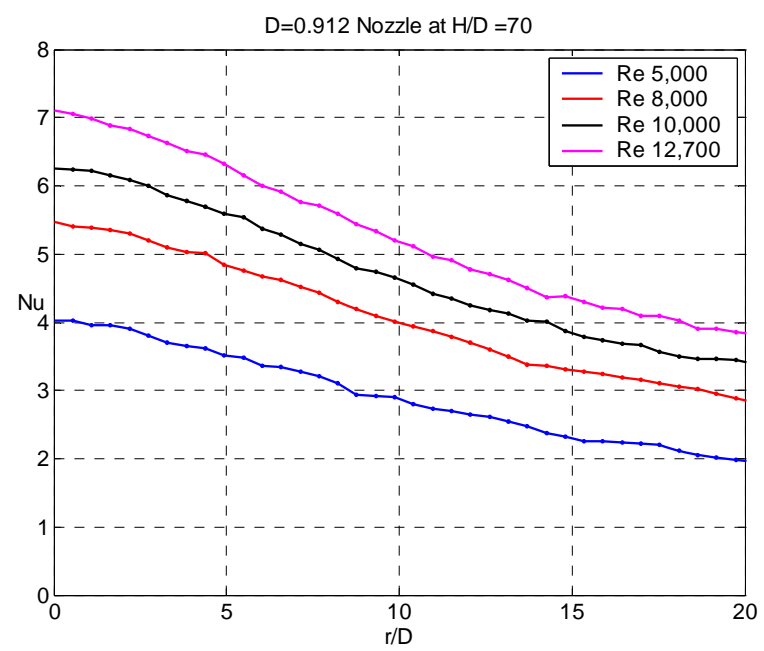

Figure 6: $\mathrm{D}=0.912 \mathrm{~mm}$; Reynolds number varied; $\mathrm{H} / \mathrm{D}=70$

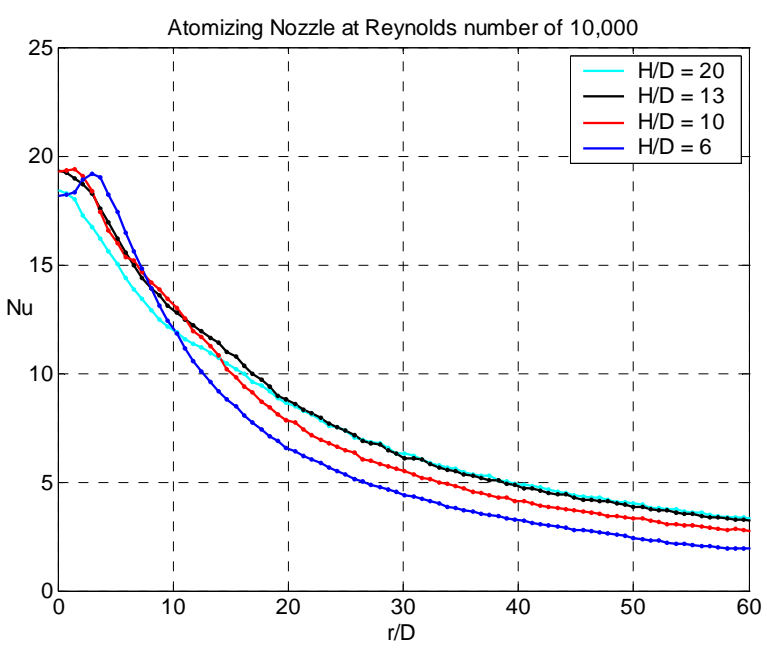

Figure 7: $\mathrm{D}=0.68 \mathrm{~mm}$; Reynolds number of 10,000; Atomizing Nozzle; H/D ratio varied 
Figures 5 and 6 show Nu distributions for a range of Reynolds number for the atomizing and the small pipe nozzle respectively. In both cases, the nozzle exit to plate spacing is 70 diameters, typical for the atomizing nozzle usage. It can be seen that the Nusselt number profiles are broadly similar but with lower Nusselt numbers for the pipe nozzle. These profiles may be slightly flatter than normal due to the spatial resolution of the sensor. Testing was not possible at this $\mathrm{H} / \mathrm{D}$ ratio for the large pipe nozzle, so this aspect could not be investigated. The effect of Reynolds number on the stagnation Nusselt number can be seen; $N u_{0} \sim R e^{0.54}$, which is similar enough to the typical exponent of 0.5 for turbulent flow

The atomizing nozzle exits in an annular profile. Although Travnicek et al, [18] have shown that annular jets where the walls are at acute angles can feature similar velocity profiles to circular jets, there still exists a reduction in jet velocity at the stagnation point. This could account for the reduced stagnation point heat transfer seen at low H/D's.

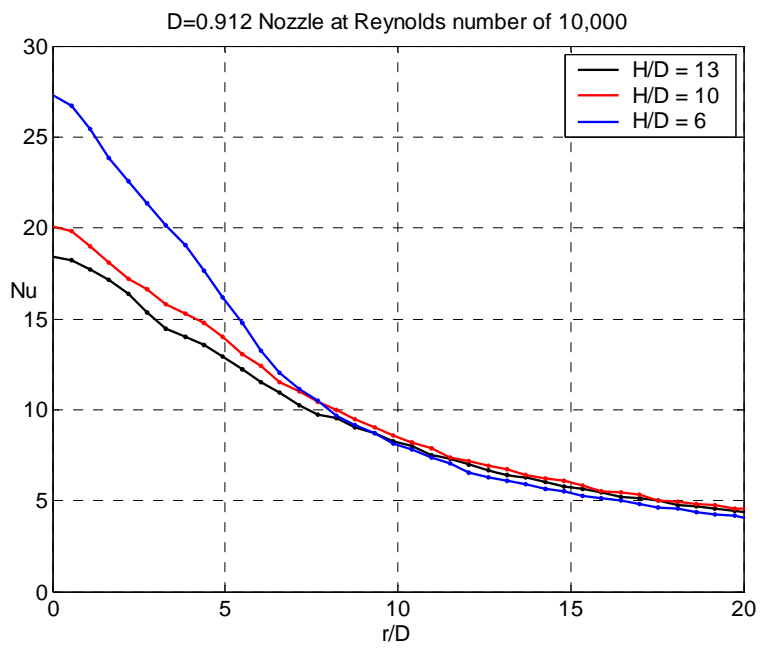

Figure 8: $\mathrm{D}=0.912 \mathrm{~mm}$; Reynolds number of 10,000; H/D ratio varied

At medium to low H/D ratios, both nozzles perform similarly, as shown in figures 7 and 8 . The pipe $(D=0.912 \mathrm{~mm})$ nozzle shows greater stagnation point heat transfer. As the H/D ratio is decreased this effect becomes more pronounced. Outside of an $\mathrm{r} / \mathrm{D}$ of two $(\mathrm{H} / \mathrm{D}=10)$ or four $(\mathrm{H} / \mathrm{D}=6)$ the atomizing nozzle shows higher heat transfer. This can be seen from figures 9 and 10 respectively. This is possibly due to the larger exit profile of the flow, i.e. the spread of the atomizing nozzle is much greater; flow field measurements are planned to confirm this.

Below an H/D ratio of six, the profiles of the atomizing nozzle are expected show a reduced stagnation point heat transfer; this is typical of annular jets at low H/D ratios [17]. This characteristic effect can be seen at an H/D ratio of six but unfortunately the current set up has not allowed the atomizing nozzle to be tested at $\mathrm{H} / \mathrm{D}$ ratios below six.

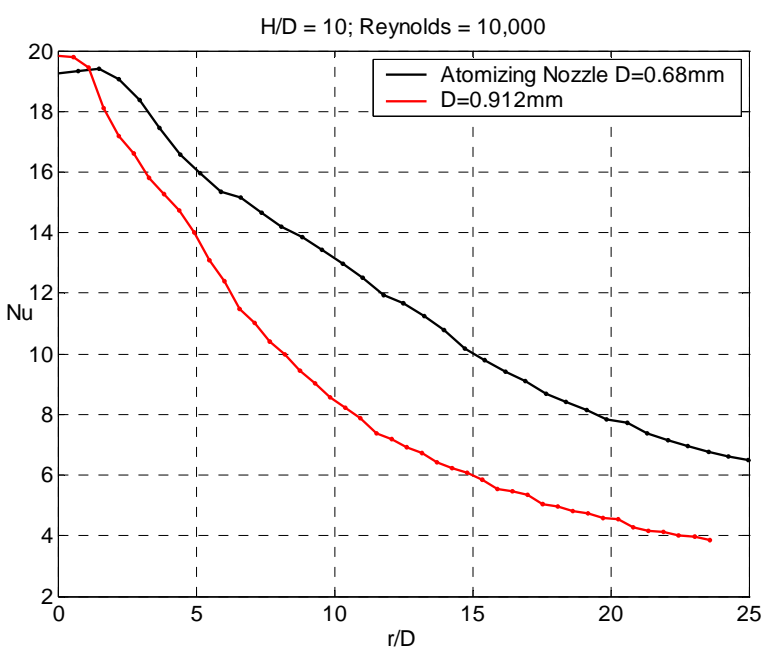

Figure 9: Comparison of Nozzle at $\mathrm{H} / \mathrm{D}=10$; Reynolds number of 10,000

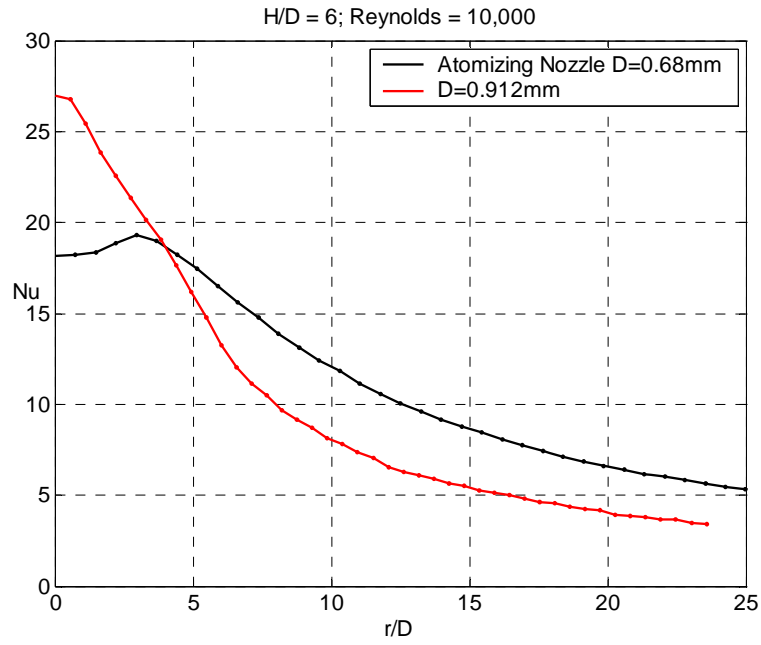

Figure 10: Comparison of Nozzle at $\mathrm{H} / \mathrm{D}=6$; Reynolds number of 10,000 


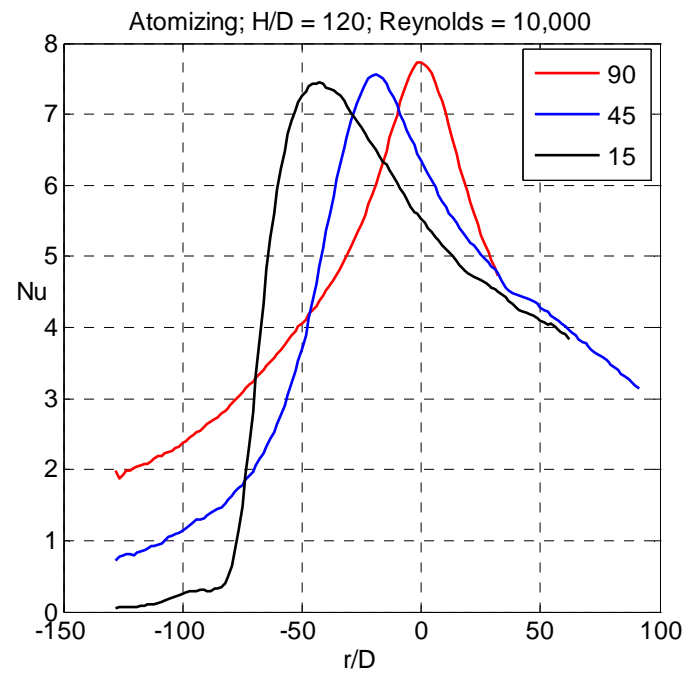

Figure 11: Effect of angle of impingement at large H/D ratio; Reynolds numbers of 10,000; Downhill is in the negative direction

Figure 11 shows the results obtained from the atomizing nozzle set at an oblique angle of impingement. In the case of a pipe nozzle, as the angle is varied away from 90 degrees, the peak heat transfer is both shifted downhill and decreased. This can be attributed to increased mass flux and radial velocities in the downhill direction. This effect has been noted by O'Donovan and Murray [9], who reasoned that the flow effectively lifts from the surface where the mean axial velocity is negative. This occurred at r/D's of approximately 1.5 or 2 at an H/D of 2, causing the wall jet boundary layer to transition to fully turbulent. The primary peak shift is evident in the atomizing nozzle, and is shifted downhill with decreasing angle. These effects should be stronger at lower H/D's.

At large H/D ratios, the atomizing jet easily outperforms the pipe jet. This could be due to the choice of $\mathrm{D}_{\mathrm{H}}$ in the nondimensional height of the nozzle. Ichimiya [14] used the value of $\mathrm{D}_{\mathrm{H}}$ in the calculation of Reynolds number and Nusselt, but deemed necessary to use $\mathrm{D}_{\mathrm{o}}$ when calculating both $\mathrm{H} / \mathrm{D}$ and $\mathrm{r} / \mathrm{D}$.

As can be seen below in figure 12 , when $D_{0}$ is used as the reference for $H / D$ and $r / D$, the results are reversed. The pipe nozzle $(\mathrm{D}=0.912 \mathrm{~mm})$ outperforms the atomizing nozzle quite considerably. If Nusselt numbers are also calculated based on the outer diameter, figure 13, this trend changes back, and the atomizing nozzle again show superior heat transfer performance.

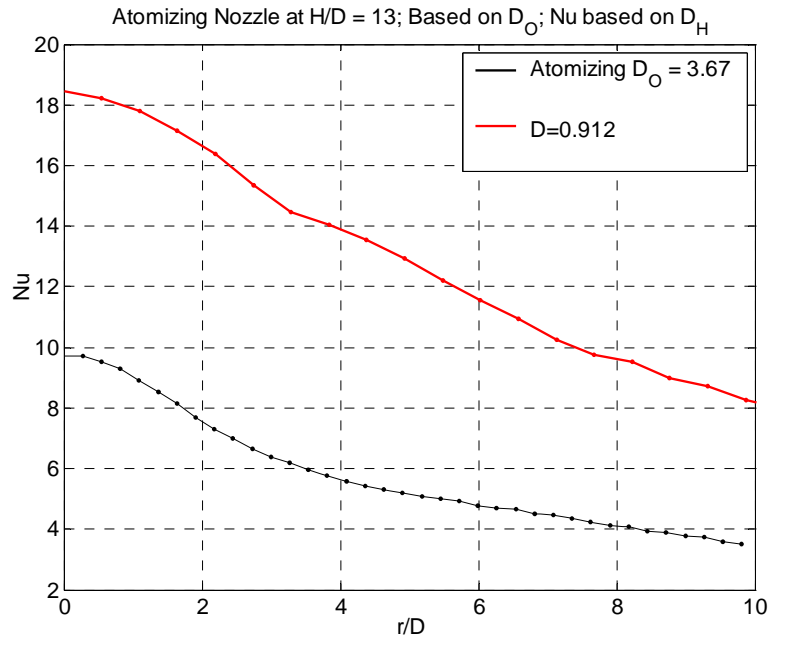

Figure 12: Atomizing Nozzle at $\mathrm{H} / \mathrm{D}=13$; Based on $\mathrm{D}_{\mathrm{o}}$; $\mathrm{Nu}$ based on $\mathrm{D}_{\mathrm{H}}$

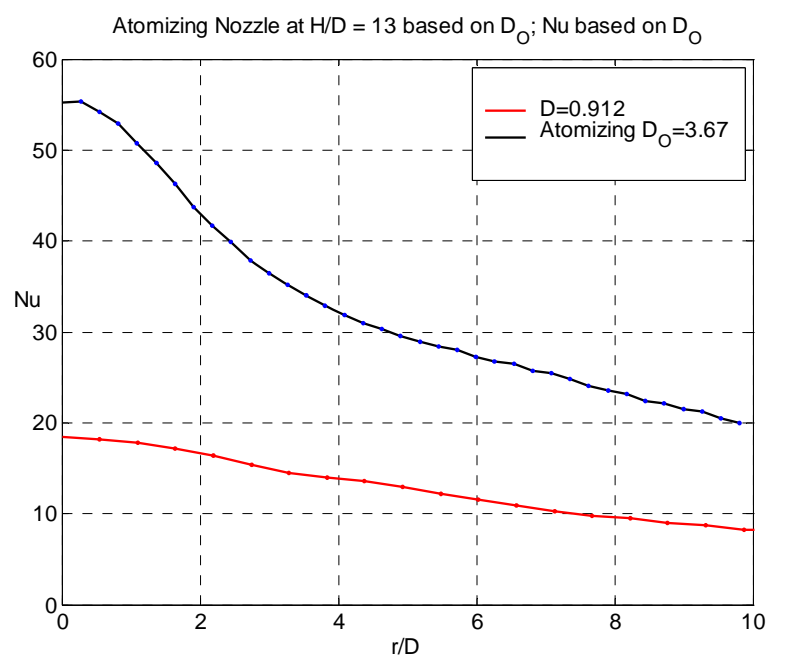

Figure 13: Atomizing Nozzle at $\mathrm{H} / \mathrm{D}=13$; Based on $\mathrm{D}_{\mathrm{O}}$; $\mathrm{Nu}$ based on $\mathrm{D}_{\mathrm{O}}$

The debate of which diameter to use seems to be compounded by the small scale jets, for which, Nusselt numbers have already been shown to not always capture the heat transfer process [12]. That the atomizing nozzle shows typical offset peak stagnation point heat transfer at $\mathrm{H} / \mathrm{D}$ ratios of six [15 17] would indicate that the choice of the hydraulic diameter would be a feasible option. 


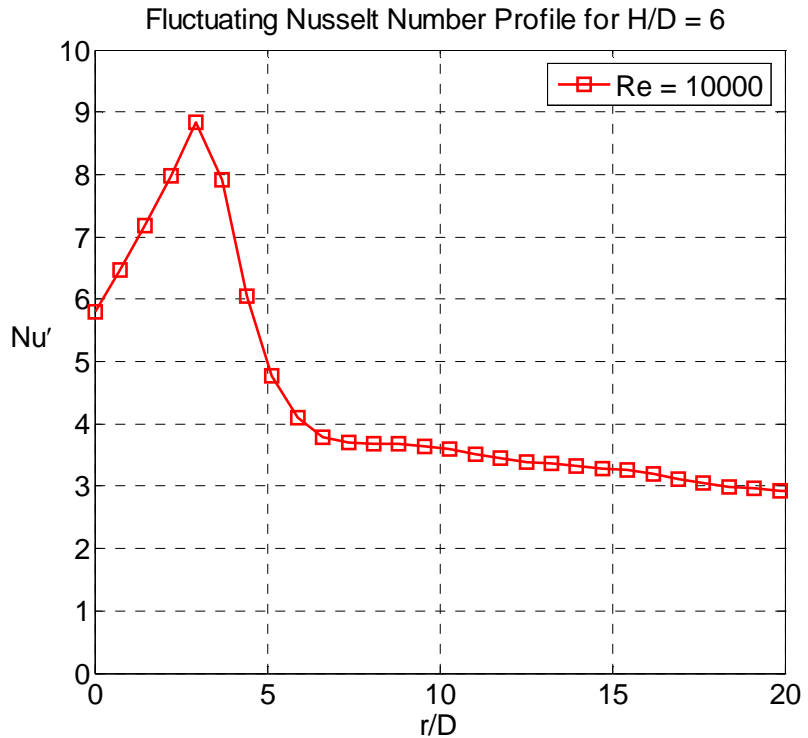

Figure 14: Fluctuating Nusselt Number for Atomizing Nozzle at $\mathrm{H} / \mathrm{D}=6$; Reynolds number of 10,000

Figure 14 shows that the fluctuating Nusselt numbers for the atomizing nozzle are much higher than for the same case with a pipe nozzle [9]. For the pipe nozzle at an H/D of six, the peak is seen at the geometric centre. However, in the case of the atomizing nozzle, this peak occurs at approximately 3-4 jet diameters out, similar to the peak Nusselt number of the same case, figures 7,10 . This is possibly due to the annular nature of the jet, [18]. This peak rapidly decreases and levels out within five or six jet diameters, in line with the case of the pipe nozzle [9]. This peak is attributed to the high turbulence injected into the wall jet flow upon impingement. An off-centre peak is seen in the case of the pipe nozzle for low H/D ratios and is attributed to the shear layer not penetrating the potential core, but in the case of the atomizing nozzle this is probably due to the flow profile.

The atomizing nozzle does appear to be following the typical bell-shaped distribution. Additionally, the effect of Reynolds number and angle of impingement show similar effects to both the pipe nozzle and previous literature [11, 15, 16]. Overall Nusselt numbers are lower than previous research [18], but this may be attributed to the confinement aspect of the nozzles.

The data recorded in this experiment has been used to compare a standard pipe nozzle to a more complex nozzle. The aim of these has been to characterise this complex nozzle, which will ultimately be used to generate a mist flow. This analysis has been used so as to determine how much of the increase in heat transfer is due to the mist and how much to that of the complex internal structure of the nozzle.

\section{CONCLUSION}

A study has been carried out to investigate the effects of nozzle geometry on local heat transfer from an impinging jet to a copper plate. The atomizing nozzle, based on air only, has been shown to provide superior convective cooling at large H/D's. The atomizing nozzle has a lower stagnation Nusselt number and tends to be lower in the immediate stagnation region, for low H/D's. At oblique angles of impingement the atomization nozzle shows peak heat transfer shift in the downhill direction; peak Nusselt numbers decrease with decreasing angle. The effect of Reynolds number and H/D spacing has been shown to be consistent with that of a straight pipe nozzle.

Further analysis of the flow field, both at nozzle exit and at impingement, is important. Further measurement of fluctuating heat transfer parameters is expected to provide further information on the characteristics of the atomizing nozzle. The authors have decided to base their diameter dependant calculations on the hydraulic diameter. Although it is difficult to determine which is better, and further investigation of the flow field may yield significant results.

\section{ACKNOWLEDGMENTS}

The authors would like to thank the Irish Research Council for Science, Engineering and Technology (IRCSET) for funding provided for this project.

The authors acknowledge the technical support staff of the Mechanical and Manufacturing Engineering Department of Trinity College.

\section{NOMENCLATURE}

A Nozzle Cross Sectional Area

$\boldsymbol{D}_{\boldsymbol{H}} \quad$ Hydraulic Diameter

$\boldsymbol{D}_{\boldsymbol{O}} \quad$ Outer Diameter of Annular Nozzle

H/D Normalised Nozzle Exit To Impingement Surface Spacing

$\mathrm{Nu} \quad$ Nusselt Number

$\mathbf{N u} \quad$ Fluctuating Nusselt Number

$\boldsymbol{P} \quad$ Wetted Perimeter of Nozzle

Pr Prandtl Number

$\boldsymbol{q}_{\text {conv }} \quad$ Convective Heat Flux

$\boldsymbol{r} / \boldsymbol{D} \quad$ Normalised Radial Location

Re Reynolds Number

$\boldsymbol{T}_{\text {adiabatic }}$ Adiabatic Wall Temperature

$\boldsymbol{T}_{\boldsymbol{j} \text { et }} \quad$ Jet Temperature

$\boldsymbol{T}_{\boldsymbol{s}} \quad$ Impingement Surface Temperature

$\boldsymbol{T}_{\text {static }} \quad$ Static Jet Temperature

\section{REFERENCES}

1 O Donovan, T. S., Murray, D. B., Torrance, A.A., Jet Heat Transfer in the Vicinity of a Rotating Grinding Wheel, 
Proc. I.Mech. E. Part C-J. Mech.Eng.Sci, Vol. 220, pp 837845, 2006.

2 Lee, S.L., Yang, Z.H., Hsyua, Y., Cooling of a Heated Surface by Mist Flow, Journal of Heat Transfer, Vol. 116, No. 1, pp. 167-172, 1994.

3 Lee, S., Park, J., Lee, P., Kim, M., Heat Transfer Characteristics During Mist Cooling on a Heated Cylinder, Heat Transfer Engineering, Vol. 26, No. 8, pp. 24-31, 2005.

4 Chatterjee, A., Deviprasath, L.J., Heat Transfer in Confined Laminar Axisymmetric Jets at Small Nozzle-plate Distances: the Role of Upstream Vorticity Diffusion, Numerical Heat Transfer, Part A, Vol. 39, pp. 777-800, 2001.

5 Viskanta, R. Heat Transfer to an Impinging Isothermal Gas and Flame Jets, Exp. Therm. Fluid Sci., Vol. 6, No. 2, pp. 111-134, 1993.

6 Mehendale, A.B., Han, J.C., Ou, S., Influence of High Mainstream Turbulence on Leading Edge Heat Transfer, Journal of Heat Transfer, Vol. 113, No. 4, pp. 843-850, 1991.

7 Choi, J., Teng, S., Han, J., Ladeinde, F., Effect of Free-stream Turbulence on Turbine Blade Heat Transfer and Pressure Coefficients in Low Reynolds Number Flows, International Journal of Heat and Mass Transfer, Vol. 47, No. 14-16, pp. 3441-3452, 2004.

8 Kito, M., Shakouchi, T. Sakamoto, T., Tsujimoto, K., Ando, T., Heat Transfer Enhancement of Round Impinging Jet by Orifice Nozzle (Effects of Contraction Area Ratio), Heat Transfer - Asian Research, Vol. 37, No. 8, pp 445-459, 2008.

9 O Donovan, T.S., Murray, D.B., "Jet impingement heat transfer - Part I: Mean and root-mean-square heat transfer and velocity distributions", International Journal of Heat and Mass Transfer, Vol. 50, pp. 3291 - 3301, 2007
10 Goldstein , R. J and Franchett, M. E., Heat Transfer From a Flat Surface to an Obliquely Impinging Jet, ASME Journal of Heat Transfer, Vol. 110, pp. 84-90, 1988.

11 Liu, T.S., Sullivan, J.P., Heat Transfer and Flow Structures in an Excited Circular Impinging Jet, Int. J. Heat Mass Transfer, Vol. 39, No. 17, pp. 3695-3706, 1996.

12 S.V. Garimella and R.A. Rice, Confined and submerged liquid jet impingement heat transfer, Journal of Heat Transfer 117 (1995), pp. 871-877.

13 Deborah V. Pence, Paul A. Boeschoten, and James A. Liburdy, Simulation of Compressible Micro-Scale Jet Impingement Heat Transfer, J. Heat Transfer -- June 2003 -Volume 125, Issue 3, 447 (7 pages)

14 Ichimiya, K, "Heat Transfer characteristics of an annular turbulent impinging jet with a confined wall measured by thermosensitive liquid crystal", Heat and MAss Transfer, Vol. 39, pp. 545-551, 2003.

15 Sozbir, N., Chang, Y.W., Yao, S.C., Heat Transfer of Impacting Water Mist on High Temperature Metal Surfaces, Transactions of the ASME, Vol. 125, pp. 70-74, 2003.

16 Shadlesky, P.S., Stagnation Point Heat Transfer for Jet Impingement to a Plane Surface, AIAA Journal, Vol. 21, pp. 1214-1215, 1983.

17 Chattopadhyay, H., Numerical investigations of heat transfer from impinging annular jet, International Journal of Heat and Mass Transfer, Vol. 47, No. 14-16, pp. 3197-3201, 2004.

18 Travnicek, Z, Peszynski , K, Hosek, J, Wawrzyniak, S, "Aerodynamic and mass transfer characteristics of an annular bistable impinging jet with a fluidic flip-flop control", International Journal of Heat and Mass Transfer, Vol.46, pp. 1265-1278, 2003. 